\title{
PESQUISA: O COMPORTAMENTO DO CONSUMIDOR NOS SUPERMERCADOS
}

Francisco José Grandis Rojo Professor do Departamento de Mercadologia da EAESP/FGV.

RESUMO: O autor mostra os principais resultados de uma pesquisa, realizada para sua tese de doutorado, sobre o comportamento dos consumidores nos supermercados. Analisa a importância da orientação dos esforços para o melhor atendimento dos consumidores e oportunidades de aprimoramento dos supermercados, particularmente no que diz respeito a atendimento e qualidade em produtos perecíveis.

ABSTRACT: The author presents the main results of a research, carried out for his Ph.D. thesis, which regards consumer behavior in supermarkets. He analyses the importance of making efforts in order to offer better services and the opportunities to improve supermarkets, especially concerning the quality of perishable products.

PALAVRAS-CHAVE: supermercados, serviços, qualidade, satisfação dos consumidores.

KEY WORDS: supermarkets, services, quality, consumers' satisfaction. 
Diante de uma competitividade crescente, os dirigentes de supermercados têm reconhecido cada vez mais a importância de orientar esforços no sentido de conhecer e atender melhor seus consumidores. Visando a contribuir com o processo de melhor conhecimento do mercado e a orientação de esforços para $o$ atendimento do consumidor, este trabalho mostra:

- resultados de pesquisas domiciliares realizadas durante o ano de 1997 com 1.400 consumidores em São Paulo, Paraná e Minas Gerais, apresentando uma avaliação da imagem dos supermercados que freqüentam, bem como oportunidades para melhoria;

- resultados de quatro discussões em grupo realizadas em setembro de 1997 com consumidores de supermercados na Grande São Paulo cujo perfil está demonstrado no Quadro 1.

\section{Quadro 1 - Perfil dos consumidores de} supermercados da Grande São Paulo

\begin{tabular}{|l|l|l|}
\hline GRUPOS & FADA ETARIA & CLASSE SOCIAL \\
\hline Grupo 1 & 25 a 35 anos & A/B+ \\
\hline Grupo 2 & 40 a 55 anos & A/B+ \\
\hline Grupo 3 & 25 a 35 anos & B-/C \\
\hline Grupo 4 & 40 a 55 anos & B-/C \\
\hline \hline
\end{tabular}

- considerações baseadas em entrevistas em profundidade com 15 dirigentes de supermercados na Grande São Paulo.

\section{ORIENTAÇÃO PARA A SATISFAÇÃO DO CONSUMIDOR}

Antes de apresentarmos os resultados obtidos por meio dos levantamentos descritos anteriormente, gostaríamos de ressaltar a importância do esforço orientado da empresa para a satisfação de seu consumidor. Em um supermercado, além, naturalmente, da qualidade dos produtos comercializados pela loja, é fundamental a qualidade em serviços para conquistar a satisfação de seus clientes.

Berry \& Parasuraman' destacam que o desempenho confiável e preciso do serviço é o coração da excelência do marketing. Existem circunstâncias em que a empresa oferece um serviço de forma descuidada, comete erros que poderiam ser evitados ou faz promessas sedutoras que não são cumpridas, o que estremece a confiança do cliente e abala sua imagem de excelência em serviço. A confiabilidade dos consumidores em relação aos serviços oferecidos pela empresa também está associada à possibilidade de maiores lucros, conforme mostra a Figura 1.

EM UM SUPERMERCADO, ALÉM, NATURALMENTE, DA QUALIDADE DOS PRODUTOS COMERCIALIZADOS PELA LOJA, É FUNDAMENTAL A QUALIDADE EM SERVIÇOS PARA CONQUISTAR A SATISFAÇÃO DE SEUS CLIENTES.

\section{A COMPANHIA VOLTADA PARA O CLIENTE}

Reforçando essa percepção, no que diz respeito à orientação para a qualidade em produtos e serviços, Whiteley ${ }^{2}$ mostra que a empresa efetivamente voltada para o cliente tem ingredientes que denomina os "sete imperativos fundamentais", conforme demonstra a Figura 2.

Cada um desses ingredientes é caracterizado por Whiteley da seguinte maneira:

- Crie uma visão que preserve o cliente: todos os funcionários da empresa, desde o presidente, devem estar empenhados na missão de satisfazer os clientes.

- Sature sua empresa com a voz do cliente: deve ser criada uma real intimidade entre a empresa e o cliente, revolucionando sua conduta e mudando a posição competitiva.

- Aprenda com os vitoriosos: as grandes empresas não conseguem e nem tentam esconder seu estilo de fazer negócios. Procure estudar seus métodos e filosofia.
1. BERRY, L., PARASURAMAN, A. Serviços de marketing. competindo através da qualidade. São Paulo: Maltese, 1992.

2. WHITELEY, R. C. A empresa totalmente voltada para o cliente. Rio de Janeiro: Campus, 1992. 
Aqueles que estudam os vitoriosos fortalecem seu compromisso em servir os próprios clientes.

- Libere os defensores de seus clientes: a maioria dos empregados quer servir bem os clientes e um dos fatores mais fortemente relacionados à permanência dos funcionários na organização é a percepção de que a empresa está cumprindo essa função. Os dirigentes devem, portanto, mostrar aos funcionários que a tarefa primordial na empresa é servir aos clientes.

- Derrube as barreiras ao desempenho conquistador de clientes: quanto mais se aprende sobre qualidade, mais se percebe que devem ser eliminadas quaisquer barreiras que prejudiquem o atendimento aos clientes.

- Esteja sempre medindo: nas organizações em processo mais acelerado de melhoria, mede-se tudo o que possa informar sobre a satisfação do cliente. Devem ser analisados não apenas seu próprio passado e os desejos dos clientes, mas também o desempenho de quem, em qualquer parte do mundo, esteja realizando melhor do que você uma tarefa semelhante.

- Faça o que você diz: dirigentes bemsucedidos que cumprem o que prometem, com enfoque no cliente, estão criando uma nova visão da liderança em qualida- de. Líderes de corporações que efetivamente buscam a melhoria constante de qualidade estão sempre aprendendo, acreditando e investindo nas pessoas.

\section{A PERCEPÇÃO DOS CONSUMIDORES EM RELAÇÃO A QUALIDADE E SERVIÇOS NOS SUPERMERCADOS}

A partir do reconhecimento da importância da orientação dos esforços para o excelente atendimento ao consumidor, apresentamos a seguir alguns dados visando a contribuir para o entendimento do comportamento de compra dos consumidores em supermercados.

\section{Atributos considerados para a escolha do supermercado}

O Gráfico 1 mostra os atributos mais citados pelos consumidores para a escolha do local das compras. Para o levantamento dessas informações, foi solicitado a cada entrevistado que citasse os três atributos mais importantes para escolha do supermercado em que faz suas compras.

Uma vez identificados os atributos mais importantes, foi solicitado aos consumidores que fizessem uma avaliação desses atributos

Figura 1 - Benefícios potenciais da qualidade em serviços

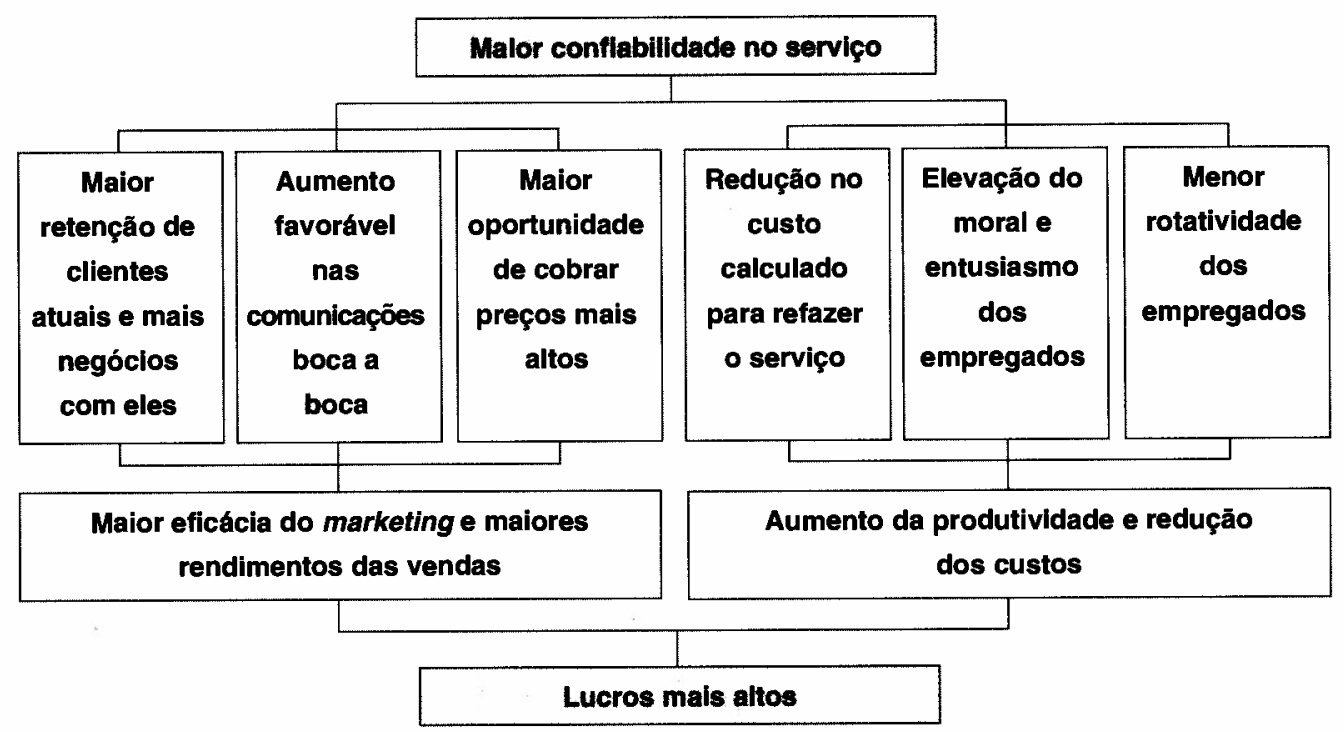

Fonte: BERRY, L., PARASURAMAN, A. Serviços de marketing: competindo através da qualidade. Sāo Paulo: Maltese, 1992. p.32. 
para cada supermercado que costuma frequientar. Cabe ressaltar que geralmente um cousumidor frequienta pelo menos dois supermercados diferentes para abastecer sua casa.

O Gráfico 2 mostra o porcentual de consumidores que classificam os supermercados em que fazem suas compras como excelentes em cada um dos principais atributos.

É interessante ressaltarmos que os consumidores de classe C/D se mostram mais satisfeitos do que os de classe A/B quanto aos supermercados em que fazem suas compras. Por meio das discussões em grupo percebemos que parece haver maior aceitação desse primeiro segmento em relação ao que os supermercados oferecem; isso ocorre, em parte, porque os consumidores de classe $\mathrm{C} / \mathrm{D}$ têm menos referencial de lojas com qualidade elevada. Por exemplo, é maior a incidência de consumidores de classe $A / B$ que conhecem lojas no exterior, com padrão operacional considerado melhor.

\section{A importância dos preços competitivos}

Como podemos perceber, os preços baixos, ofertas e promoções são o principal atributo destacado tanto pelos consumidores de classe A/B como pelos de classe C/D. Esses dados correspondem à percepção dos super- mercadistas entrevistados na Grande São Paulo, que destacam o preço como principal fator de atração dos consumidores.

Por meio das discussões em grupo, podemos perceber que os consumidores realmente dão muita importância ao preço, mas também notamos que o supermercado não será capaz de reter seus clientes se, além de preços competitivos, não oferecer bom atendimento, qualidade, higiene e variedade. Com o mercado competitivo, além de preços baixos, os supermercados estāo oferecendo mais qualidade $\mathrm{e}$ serviços; dessa forma, o cliente irá escolher aquele que lhe proporcionar maior valor.

Como também consideram os supermercadistas, o cliente raramente está satisfeito com os preços do supermercado - "quanto mais baixo melhor". Isso está refletido no fato de apenas $17 \%$ dos consumidores considerarem excelentes os preços das lojas que frequientam. Os consumidores consideram que ainda é muito importante comparar preços entre os supermercados, apesar da estabilidade econômica.

Obviamente o supermercado sempre deverá procurar ser competitivo em preços, uma vez que essa variável é importante para os consumidores. No entanto, acreditamos que essa competitividade deve ser conseqüência da eficiência e da produtividade, sem necessariamente sacrificar cada vez mais suas margens de lucro.

Figura 2 - Sete imperativos fundamentais para a qualidade
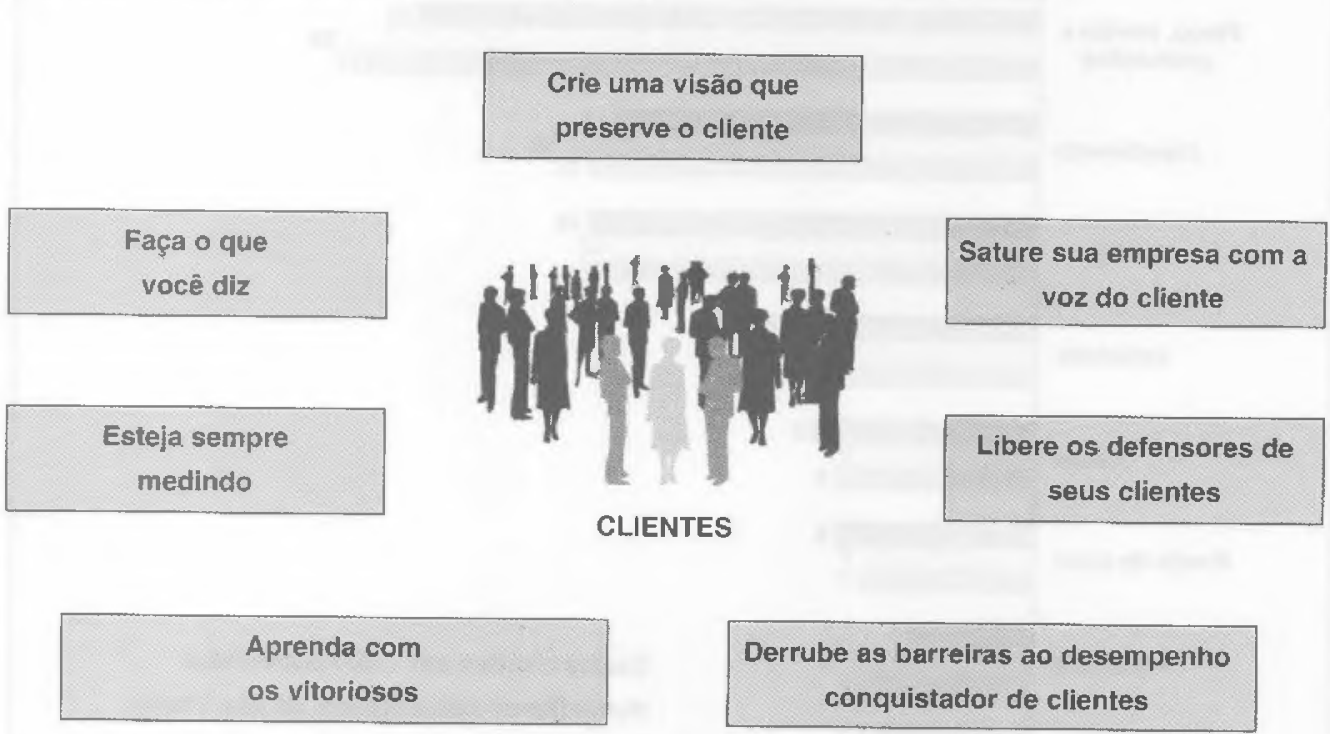

Derrube as barreiras ao desempenho conquistador de clientes

Fonte: Adaptado de WHITELEY, R. C. Empresa totalmente voltada para o cliente. Fio de Janeiro: Campus, 1992. 


\section{Atendimento}

$\mathrm{O}$ atendimento aparece como o segundo atributo mais importante, praticamente com a mesma frequiência que a qualidade. Essa percepção também corresponde ao manifestado pelos supermercadistas, que consideram o atendimento a variável mais importante, após o preço. $\mathrm{O}$ atendimento é percebido pelos próprios supermercadistas como fator de atração e principalmente de fidelização do consumidor. Para os supermercadistas é fundamental que o cliente sinta que foi atendido com cordialidade e eficiência durante suas compras na loja.

Podemos perceber, pelas discussões em grupo, que os consumidores realmente dão bastante importância ao atendimento nos supermercados. Curiosamente, o consumidor de classe C/D dá ao atendimento tanta importância, ou até mais, do que o de classe $\mathrm{A} /$ B. Para o consumidor de classe C/D é forte o sentido de que ele "está pagando pelo que está comprando" e por isso quer ser respeitado e bem atendido.

Durante a maior parte do tempo, durante as compras em um supermercado, o consu- midor tem pouco contato pessoal com os funcionários, a não ser no açougue, quando há atendimento pessoal, na compra de frios, frutas e principalmente na frente de caixa, no momento de pagar. Assim, muito da imagem do atendimento pessoal é atribuído ao pessoal da frente de caixa e, como ressaltam os consumidores, muitos supermercados têm pessoal despreparado para essa função.

Do total dos consumidores, $53 \%$ consideram excelente $o$ atendimento nos supermercados que freqüentam, mas deixam claro que é preciso continuar a melhorar o padrão, demonstrando um grau crescente de exigência. Podemos considerar que existe muita oportunidade para melhoria no atendimento, buscando maior satisfação de quase metade do total de consumidores, que não considera $o$ atendimento excelente.

\section{Qualidade}

Também é uma variável importante, assim como o atendimento. Durante as discussões em grupo, os consumidores demonstraram que a imagem de qualidade da loja está associada principalmente a dois fatores:

Gráfico 1 - Atributos para escolha do local de compras

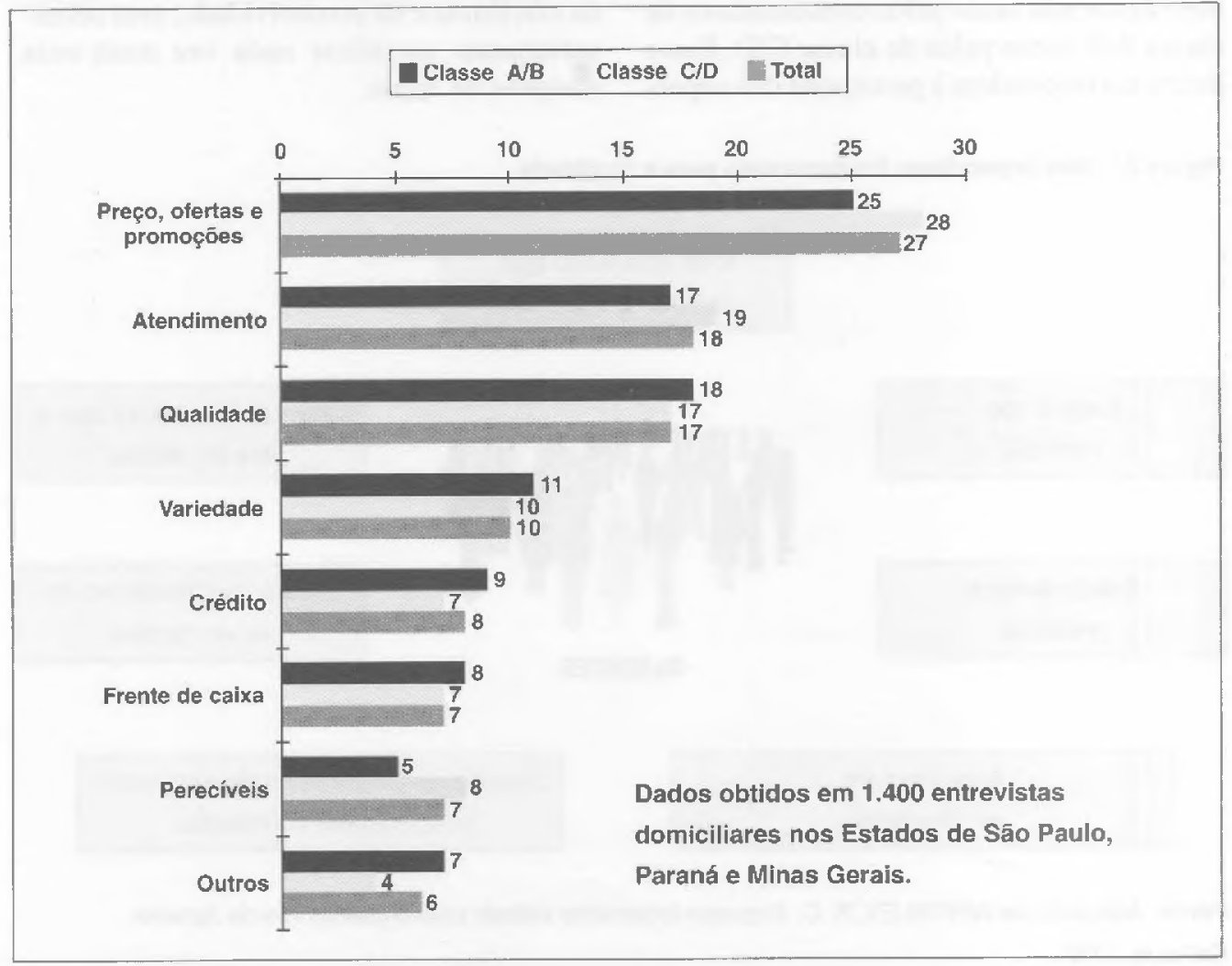


- padrão arquitetônico e tecnológico do supermercado;

- produtos perecíveis.

A loja moderna reforça a percepção que o consumidor tem em relação à qualidade do supermercado. No entanto, é pelos produtos perecíveis que os consumidores baseiam grande parte de sua percepção em relação à qualidade da loja. Os produtos industrializados, como, por exemplo, os enlatados, são iguais em todos os supermercados, mas, quando o cliente compara a qualidade de uma fruta ou verdura, identifica mais facilmente as diferenças entre lojas concorrentes. Dessa forma, os consumidores ressaltam que o supermercado precisa cuidar muito bem da exposição e da qualidade dos produtos perecíveis.

A qualidade das lojas freqüentadas é considerada excelente por $51 \%$ dos consumidores. Quando consideramos a avaliação dos perecíveis, verificamos que esse porcentual cai para $35 \%$, demonstrando que muitos consumidores se mostram menos satisfeitos com os supermercados. Nas discussões em grupo, os consumidores são ainda mais críticos, deixando claro que muitos detalhes precisam ser aprimorados nas lojas, desde a limpeza em banheiros para clientes, pias nas lojas para lavar as mãos após o manuseio de frutas e verduras, até a conservação de pisos e equipamentos.

\section{Variedade}

Para muitos consumidores, a variedade é também um fator importante de diferenciação para a escolha do supermercado. Os supermercadistas reconhecem a importância dessa variável e demonstram isso na medida em que estão procurando aplicar cada vez mais o conceito de gerenciamento de categorias em suas lojas. Para o varejista, a gestão da variedade pode ter forte impacto em seu investimento e giro de estoques, afetando diretamente a rentabilidade da loja.

Os consumidores, mesmo os de classe $\mathrm{C} /$ $\mathrm{D}$, demonstram que gostam de comprar deter-

Gráfico 2 - Porcentual de consumidores que classificam o supermercado em que fazem compras como excelente

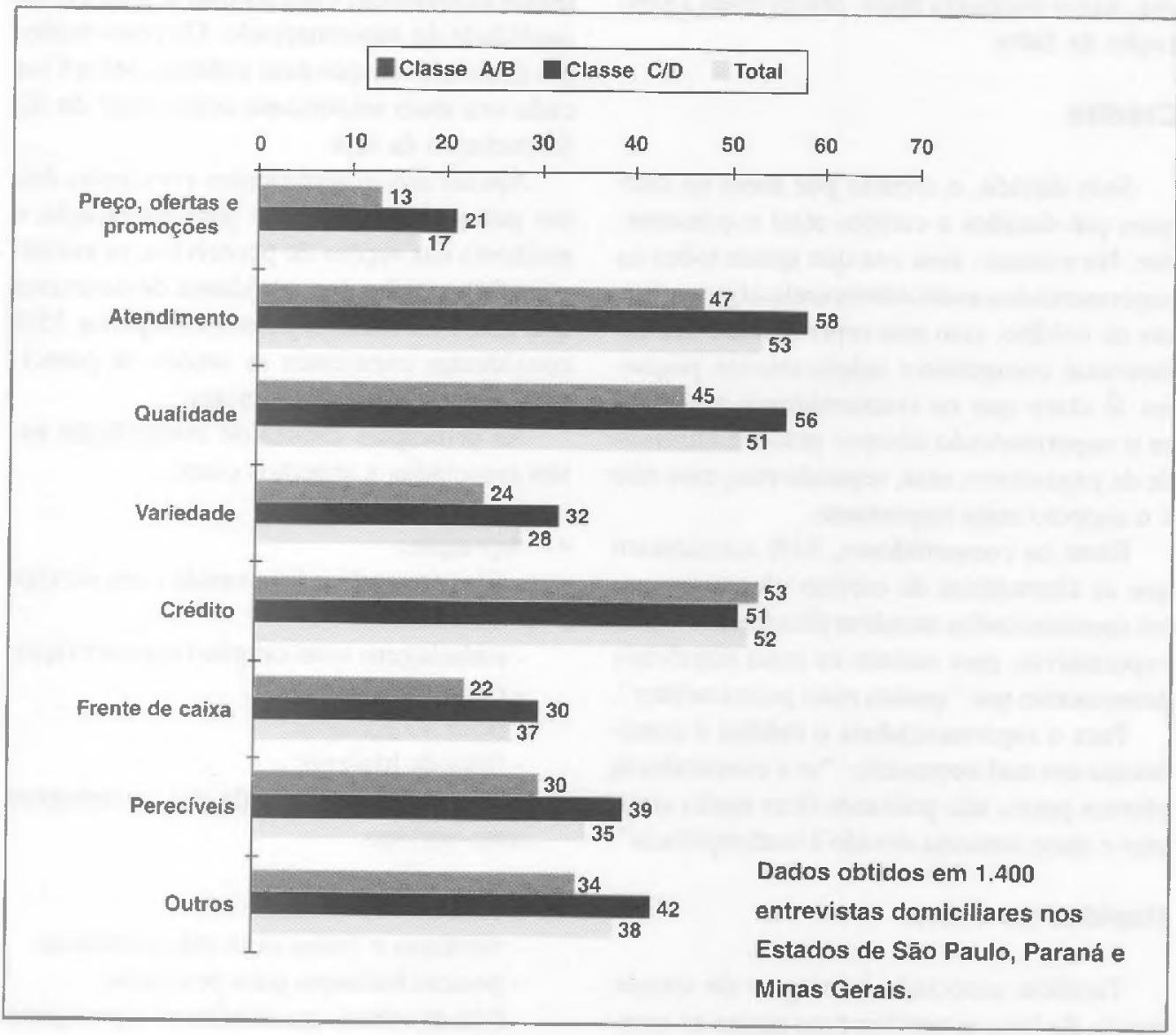

RAE * v. $38 \cdot$ ก. $3 \cdot$ Jul./Set. 1998 
minadas marcas, que reconhecem em função da qualidade. Podemos perceber, em todas as reuniões com consumidores, que tão importante quanto a definição da variedade para a loja é a constância da presença dos produtos no ponto-de-venda. Os clientes demonstram muita irritação quando não encontram determinados produtos que estão habituados a comprar.

A variedade é considerada excelente por apenas $28 \%$ dos consumidores, apesar de destacarem que a maior abertura para produtos importados trouxe mais alternativas para suas compras. Essa constatação também é verificada pela pesquisa do The Marketing Group, mostrando que a variedade é um dos atributos que mais melhoraram a partir da entrada de produtos importados.

Entre os consumidores de classe mais alta, apenas $24 \%$ consideram excelente a variedade de produtos oferecidos pelos supermercados que frequientam. Grande parte da fraca avaliação da variedade nas lojas parece estar associada à falta de constância de produtos considerados importantes. O consumidor experimenta um novo produto do qual gosta e, na próxima compra, não o encontra mais, reforçando a sensação de falta.

\section{Crédito}

Sem dúvida, o crédito por meio de cheques pré-datados e cartões atrai o consumidor. No entanto, uma vez que quase todos os supermercados estão oferecendo alguma forma de crédito, isso tem representado um diferencial competitivo relativamente pequeno. É claro que os consumidores apreciam se o supermercado oferece prazo e facilidade de pagamento, mas, segundo eles, esse não é o aspecto mais importante.

Entre os consumidores, $52 \%$ consideram que as alternativas de crédito oferecidas pelos supermercados atendem plenamente a suas expectativas, mas mesmo os mais satisfeitos demonstram que "quanto mais prazo melhor".

Para o supermercadista o crédito é considerado um mal necessário: "se a concorrência oferece prazo, não podemos ficar muito atrás, mas o risco aumenta devido à inadimplência".

\section{Rapidez no caixa}

Também associada à imagem de atendimento da loja, a rapidez para pagar as com- pras parece ser um ponto de estrangulamento nos supermercados. Apesar da informatização, para muitos consumidores esse ainda é o pior momento na loja: "é hora de pagar e ainda ter de esperar na fila".

Apenas $27 \%$ dos consumidores consideram excelente a frente de caixa nas lojas que frequientam. A pesquisa do The Marketing Group também reforça a baixa satisfação dos consumidores nesse atributo.

As discussões em grupo deixam claro a insatisfação e a necessidade de melhoria nos processos e no atendimento na frente de caixa. Queixas como falta de troco, demora para passar o produto, falta de cuidado no manuseio das compras e mau humor dos operadores de caixa são comuns entre os consumidores. Uma das principais queixas ocorre quando existem grandes filas e alguns caixas estão fechados, o que é percebido como total falta de respeito ao cliente.

\section{Perecíveis}

Como visto anteriormente, os perecíveis muito contribuem para formar a imagem de qualidade do supermercado. Os consumidores demonstram que esse atributo deverá ser cada vez mais importante como fator de diferenciação da loja.

Apesar dos investimentos crescentes feitos pelos supermercados para ampliação e melhoria das seções de perecíveis, as avaliações feitas pelos consumidores demonstram que ainda há muito a percorrer; apenas $35 \%$ consideram excelentes as seções de perecíveis das lojas que frequientam.

As principais causas de insatisfação estão associadas a aspectos como:

\section{- Açougue:}

- filas (quando a loja vende com serviço de atendimento);

- embalagens com sangue (auto-serviço);

- cortes inadequados;

- odor no açougue;

- falta de higiene;

- variedade inadequada das embalagens auto-serviço.

- Frutas e verduras:

- verduras e frutas com má aparência;

- poucas balanças para pesagem;

- falta de cortesia no atendimento (pesagem); 
- falta de padrão nos produtos (variação de qualidade na mesma banca).

- Frios e laticínios:

- produtos com pouco tempo para vencer a validade;

- má conservação de produtos refrigerados.

\section{- Padaria:}

- pouca variedade, principalmente na confeitaria;

- falta de qualidade na apresentação dos produtos.

Pelas discussões em grupo, podemos perceber que existem muitas necessidades de melhoria nas seções de perecíveis dos supeimercados. No entanto, os consumidores ressaltam que há uma qualidade crescente nessas seções principalmente entre as grandes lojas, que se tornam mais atraentes e, para muitos desses consumidores, a principal opção como local de compra.

De qualquer forma, se analisarmos o setor supermercadista de maneira mais geral, verificamos que grande parte das compras de perecíveis ainda é feita fora dos supermercados, em açougues, feiras, sacolões e padarias, conforme mostra o Gráfico 3 .
Nos produtos de mercearia (91\%), frios e laticínios $(89 \%)$ e bazar $(75 \%)$, os supermercados mostram uma forte participação como local de compras para os consumidores. No entanto, nas seções de perecíveis como carnes e aves ( $55 \%$ ), frutas e verduras $(45 \%)$ e padaria $(28 \%)$, os supermercados ainda têm participação relativamente baixa. $O$ desenvolvimento dessas seções ainda representa uma oportunidade de crescimento para muitos supermercados. São seções que comercializam produtos comprados frequientemente, podendo criar maior fluxo de clientes para os supermercados. Os consumidores deixam claro que uma das principais dificuldades encontradas, principalmente pelas lojas de porte médio e pequeno, é a obtenção de uma boa qualidade dos produtos.

A partir das discussões em grupo, podemos perceber claramente que os supermercados têm melhorado as seções de perecíveis, atendendo a uma solicitação crescente dos consumidores. Para eles, é importante poder fazer a totalidade de suas compras em um mesmo local. Assim, à medida que os supermercados forem aprimorando as seções de perecíveis, deverão

Gráfico 3 - Participação dos supermercados, por seção, nas compras dos consumidores

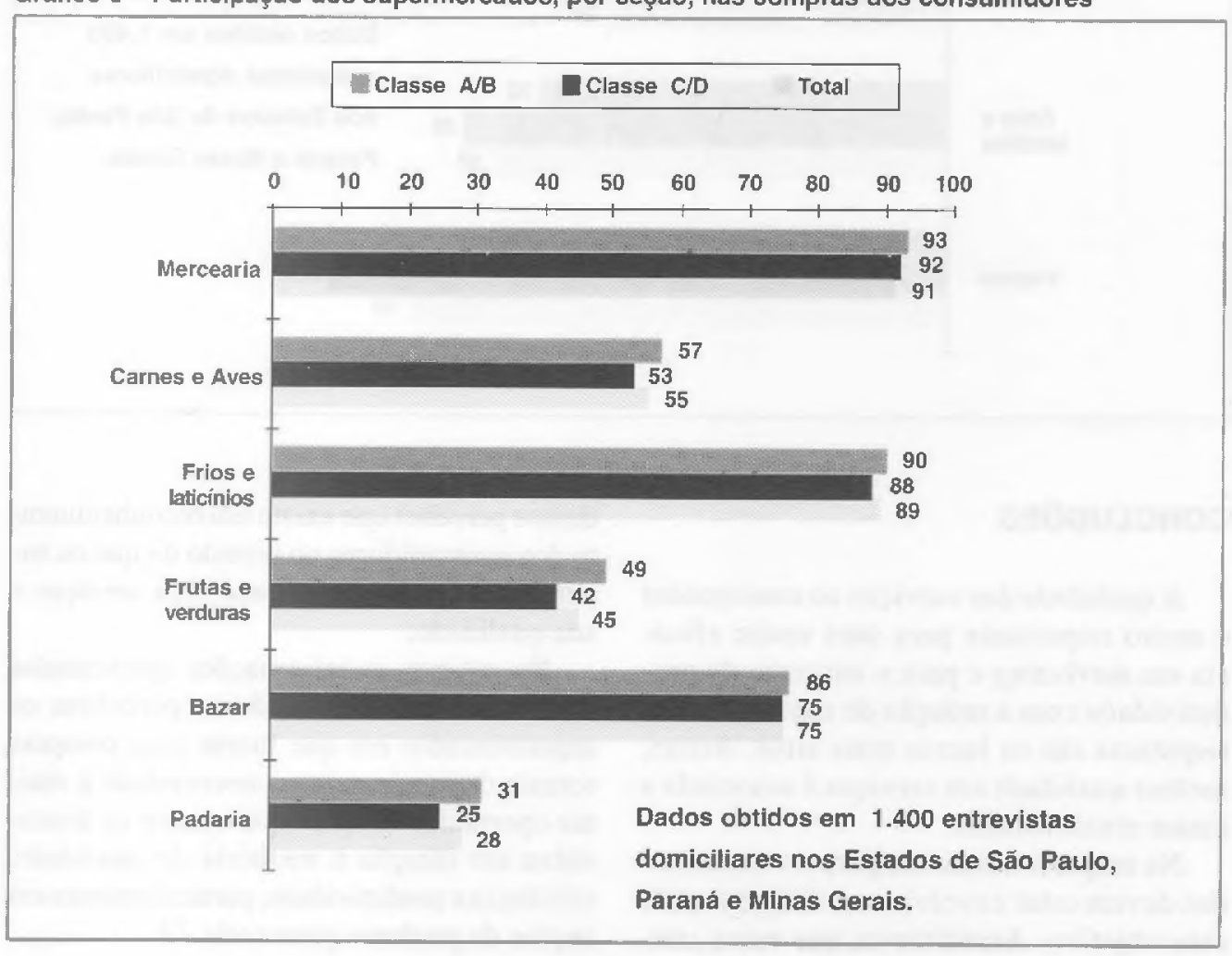

RAE * v. $38 \cdot$ - n. $3 \cdot$ Jul./Set. 1998 
conquistar maior fatia de mercado nesses segmentos.

Visando a oferecer alguma contribuição para o direcionamento de esforços nesse sentido, apresentamos, no Gráfico 4, o porcentual de consumidores que consideram excelentes as seções de perecíveis dos supermercados que freqüentam.

Também aqui podemos verificar que o grau de satisfação das classes C/D com as seções de perecíveis dos supermercados é maior do que o de clientes de classes A/B. Os dados também reforçam a percepção de que existe espaço para melhoria da imagem das seções de perecíveis junto aos clientes das lojas. ceitos são muito relevantes para o setor de supermercados, uma vez que se trata de uma atividade em que os consumidores circulam nas lojas em contato direto com produtos e com funcionários.

Com base em entrevistas com supermercadistas, podemos perceber que existe uma preocupação crescente com a busca do aprimoramento de seu negócio para conseguir maior satisfação e fidelidade dos consumidores. A própria competitividade torna esse esforço uma condição indispensável para a sobrevivência em longo prazo.

Com base nas pesquisas apresentadas e durante as discussões em grupo, também pu-

Gráfico 4 - Porcentual de consumidores que consideram excelentes as seçōes de pereciveis dos supermercados em que fazem compras

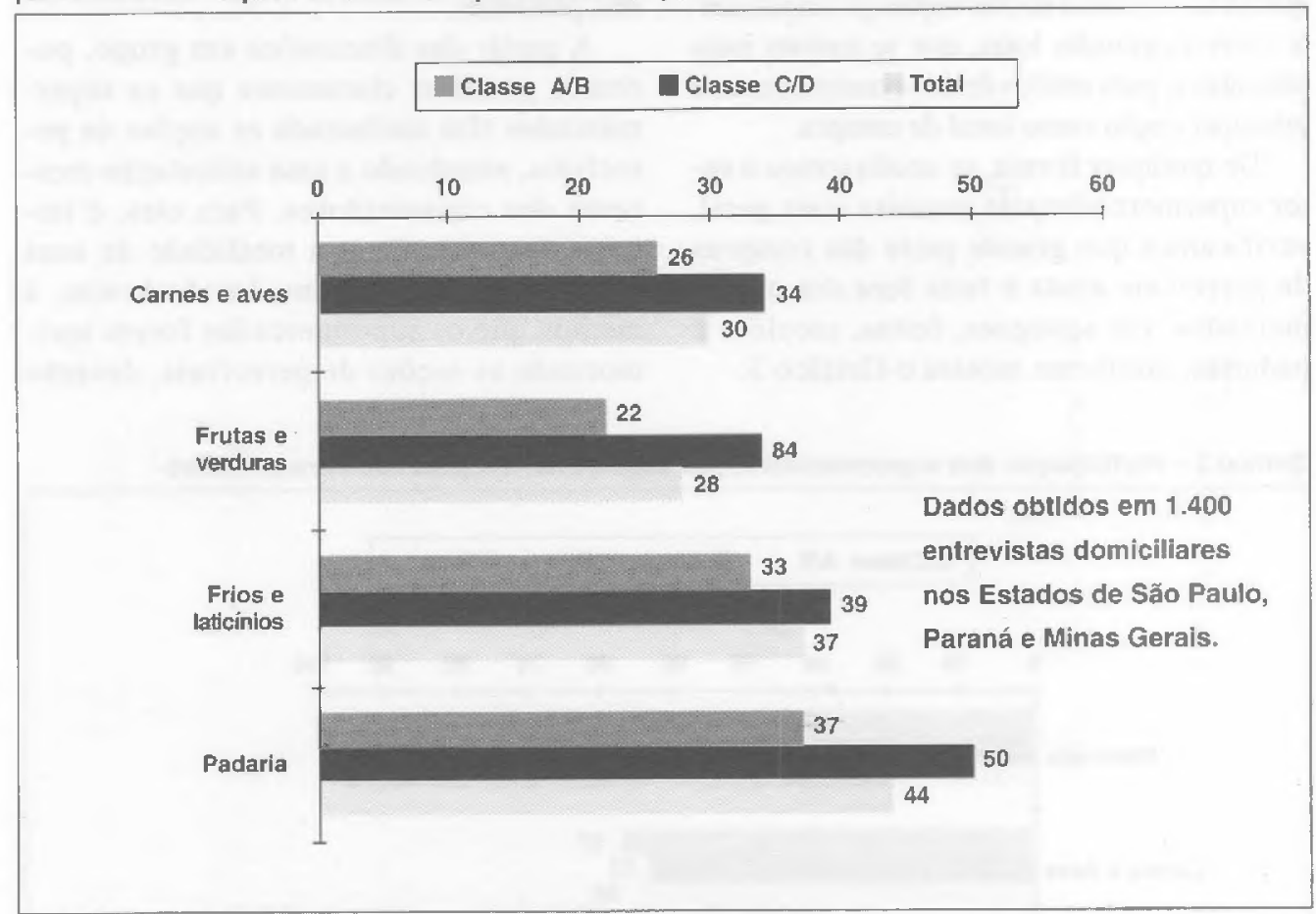

\section{CONCLUSÕES}

A qualidade dos serviços ao consumidor é muito importante para uma maior eficácia em marketing e para o aumento da produtividade com a redução de custos. A conseqüência são os lucros mais altos. Assim, melhor qualidade em serviços é associada a maior rentabilidade.

$\mathrm{Na}$ empresa orientada para o cliente, todos devem estar envolvidos e dirigidos para esse objetivo. Acreditamos que esses con- demos perceber que existe um reconhecimento dos consumidores no sentido de que os supermercados tềm melhorado seus serviços e sua qualidade.

No entanto, as informações apresentadas sobre como os consumidores percebem os supermercados em que fazem suas compras tornam claro que existe a necessidade e muitas oportunidades para que o setor se desenvolva em direção à melhoria de qualidade, eficiência e produtividade, particularmente em seções de produtos perecíveis. 